\title{
Parasite distribution on client reef fish determines cleaner fish foraging patterns
}

\author{
Redouan Bshary ${ }^{1,2, *}$, Alexandra S. Grutter ${ }^{3}$ \\ ${ }^{1}$ Max-Planck-Institut für Verhaltensphysiologie, Seewiesen, Postfach 1564, 82305 Starnberg, Germany \\ ${ }^{2}$ University of Cambridge, Department of Zoology, Downing Street, Cambridge CB2 3EJ, United Kingdom \\ ${ }^{3}$ Department of Zoology and Entomology, The University of Queensland, Brisbane, Queensland 4072, Australia
}

\begin{abstract}
Recent evidence suggests that cleaner fish Labroides dimidiatus effectively control parasite densities on client reef fish that actively visit them to have parasites and dead or infected tissue removed. These findings support the hypothesis that clients benefit from cleaning. However, they do not show how cleaners reduce the parasite load of their clients. Cleaners could selectively feed on parasites or parasite removal could be a side product of cleaners foraging indifferently on the client surface, resulting in the removal of healthy mucus and scales also. To investigate cleaner fish foraging behaviour, we infected individuals of the surgeon fish Ctenochaetus striatus, with parasitic monogeneans on one body side, while the other body side was parasite free. We then allowed these clients to interact with $L$. dimidiatus. We found that the duration of interactions depended on parasite load, and that cleaners spent both more time and took more bites per time unit on the infected than on the uninfected side. Our data thus support the idea that parasite abundance determines food patch quality for cleaners. The overall outcome of cleaning interactions is thus likely to benefit the clients.
\end{abstract}

KEY WORDS: Cleaning behaviour - Cooperation · Mutualism - Selective foraging $\cdot$ Labroides dimidiatus Resale or republication not permitted without written consent of the publisher

\section{INTRODUCTION}

In tropical reefs, many fish regularly visit so-called cleaner fish that apparently remove ectoparasites and dead or infected tissue from their visitors, referred to as clients (reviews by Feder 1966, Losey et al. 1999, Côté 2000). These interactions represent one of the classical examples of mutualism, but like in other supposedly mutualistic systems (Cushman \& Beattie 1991), evidence of the mutualistic nature of the interactions has not yet been confirmed (Losey et al. 1999). While the benefits to the cleaners seem to be self evident as they get food delivered to their small territories, it has been particularly difficult to show that clients also benefit

\footnotetext{
*Address for correspondence: University of Cambridge, Department of Zoology, Downing Street, Cambridge CB2 3EJ, United Kingdom. E-mail: rb286@cam.ac.uk
}

from cleaning interactions. Removal experiments of cleaning organisms yielded inconclusive evidence (Limbaugh 1961, Youngbluth 1968, Losey 1972, Gorlick et al. 1987, Grutter 1997a). In addition, it became apparent that cleaners do not only feed on parasites but also on healthy client tissue such as mucus and scales (Randall 1958, Gorlick 1980, Grutter 1997b). Losey $(1972,1977)$ looked at the mechanisms that make clients visit cleaners. He found that clients without parasites would elicit interactions and concluded that it was therefore unlikely that the presence of parasites alone triggers client solicitation of cleaning interactions. He proposed that clients might visit cleaners because the latter exploit the clients' sensory system by providing a form of tactile reward (Losey 1979, 1987). Cleaners are in almost constant contact with their clients during inspection through their pelvic fins, and cleaners sometimes even hover above the clients' back with their mouth pointing away from the clients 
to gently touch the dorsal fin areas (Potts 1973, Bshary 2001). Losey (1977) found that clients behaved towards an automatically turning brush very much like they behaved towards cleaners. Summarising the evidence, Losey (1987) proposed that clients do not benefit from cleaning interactions but visit cleaners for hedonistic reasons.

More recently, the evidence has shifted back to the original view (Limbaugh 1961, Feder 1966, Trivers 1971) that cleaning interactions are overall mutualistic. Individual clients seek cleaning interactions several

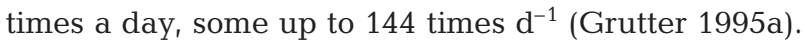
The cleaner wrasse Labroides dimidiatus feeds on up to 1200 parasites $\mathrm{d}^{-1}$ on reefs around Lizard Island, Great Barrier Reef (Grutter 1996). The most direct evidence comes from an experiment in which individuals of the wrasse Hemigymnus melapterus were placed in cages on patch reefs with cleaners either present or absent. Grutter (1999) found that individuals on patch reefs without cleaners had a 4 -fold higher parasite abundance both after $12 \mathrm{~h}$ and after $12 \mathrm{~d}$ compared to individuals on patch reefs with cleaners. The cleaners thus clearly controlled parasite abundance on these clients. In addition, parasite densities on clients determine cleaning duration. Client body size correlates with ectoparasite load and the tendency to get cleaned, both within species and between species (Grutter 1995a, Sikkel et al. 2000), and this correlation can be used to predict other variables, such as cleaner fish densities (Arnal et al. 1999). More importantly, infected fish spend more time next to a cleaner behind glass than uninfected fish, and infected fish also spend more time next to a cleaner compared to a control fish than do uninfected fish (Grutter 2001). Furthermore, Gorlick (1984) and Sikkel et al. (2000) found that cleaner fish clean infected client individuals longer than uninfected individuals of the same client species. What is still unknown is whether cleaners feed selectively on the parasites. Alternatively, cleaners could feed on the clients' surface in an opportunistic way, removing parasites and mucus according to their relative abundance. In the latter case, cleaners would still control parasite densities on their clients but would also impose costs through the deliberate removal of healthy client tissue.

In this paper, we explored whether cleaners feed selectively on client parasites. We conducted aquarium experiments using the surgeon fish Ctenochaetus striatus as the client species and Labroides dimidiatus as the cleaner. We cultured parasitic monogeneans and prepared clients that were infected with these parasites on one body side only. Half of the clients had very high parasite numbers, while the other half had numbers of parasites on them that are comparable to parasite numbers found under natural conditions
(Grutter 1994). We asked the following questions: (1) Does cleaning duration depend on parasite numbers? (2) Do cleaners spend more time on the infected side than on the uninfected side? and (3) Do cleaners take more bites (mouth contacts) per inspection time on the infected side than on the uninfected side? According to the selective foraging hypothesis, a client's quality as a food patch is determined by its number of ectoparasites. According to optimal foraging theory, an individual should spend more time on a food patch where plenty of (preferred) food items are available (Stephens \& Krebs 1986). We therefore predicted that cleaners would spend more time with highly infected clients than with normally infected clients, and that cleaners would spend more time and take more bites per time unit on the infected side than on the uninfected side. A lack of significant differences would indicate that cleaners feed randomly on the client's surface.

\section{MATERIALS AND METHODS}

Study site. The experiments were conducted in October/November 1998 at Lizard Island Research Station, Great Barrier Reef, Australia. Labroides dimidiatus is the main cleaner fish in this area (Grutter 1997).

Fish holding conditions. For our experiments, we caught wild cleaners and wild Ctenochaetus striatus from the lagoon near Lizard Island. All aquaria and round tanks in which we kept the study specimens had a direct influx of seawater. Water temperature in the aquaria thus closely matched seawater temperature. All fish were kept for at least $25 \mathrm{~d}$ to acclimate to captivity before they were used in the experiments. During this time period, the fish were trained to feed on food mashed onto Plexiglas plates (for cleaners: shrimps; for C. striatus: fish flakes mixed with shrimps). The fish adapted well to the feeding procedure and would feed while we introduced the plates to the aquarium. 10 cleaners 4.5 to $6.3 \mathrm{~cm}$ in standard length were kept in pairs in aquaria $(50 \times 30 \times 30 \mathrm{~cm})$, while $C$. striatus were kept in large round tanks $(110 \mathrm{~cm}$ diameter, $42 \mathrm{~cm}$ high) in groups of 3 to 5 individuals.

Parasite infections. We caught a total of 24 Ctenochaetus striatus 13.8 to $17.9 \mathrm{~cm}$ in standard length for the experiments. We treated 10 individuals with a praziquantal solution (ICN Biomedicals, $0.01 \mathrm{~g}$ dissolved in ethanol $\mathrm{l}^{-1}$ ), which removed all their helminthic ectoparasites (Grutter 1994). Although the fish also have parasitic isopods, these are generally lost after capture and handling (Grutter 1995b). The other 14 individuals were not treated but kept with small bar- 
rier nets $(20 \times 30 \mathrm{~cm}$ with $1 \mathrm{~mm}$ mesh size $)$ in their tanks on which the eggs of parasitic monogeneans became entangled so that hatched larvae could eventually re-infect the fish (following Ernst \& Whittington 1996). We then used the following procedure to obtain fish with one infected and one uninfected side: 1 infected C. striatus and 1 uninfected individual were anaesthetised at the same time with MS 222. We minimised the impact of anaesthetising $C$. striatus by limiting the time spent anaesthetised to 20 min during the parasite transfer. While using a stereomicroscope, monogeneans were removed from the infected fish with a thin needle and a pipette and placed on one body side of the uninfected fish. The number of successfully transferred monogeneans varied between 2 and 9. Such parasite densities are within the range found on wild individuals (Grutter 1994). The partly cleaned body side of the parasite donor was then placed in a freshwater praziquantal solution (0.005 g dissolved in ethanol in $250 \mathrm{ml}$ seawater) for $2 \mathrm{~min}$, while the body side out of the solution was regularly moistened with seawater. Praziquantal is toxic to monogeneans, and freshwater kills monogeneans through diffusion effects. The treated body side was carefully brushed to remove still attached monogeneans while the fish recovered in seawater. In total, between 12 and 104 monogeneans were removed from the body sides. As these fish would still have had similar numbers of parasites on the untreated body side (see below), they had more parasites than the fish infected by us with the parasite transfer, and also more than what is usually found under natural conditions (Grutter 1994). We thus had a group of normally infected and a group of highly infected fish.

Two fish were used to test the accuracy of the method. With the freshwater praziquantal bath almost equal number of parasites were removed from both sides (174/182 and 21/19, respectively). Only an additional $19(5.1 \%)$ and $2(4.8 \%)$ monogeneans were recovered after leaving the fish in $4 \mathrm{l}$ of praziquantal saltwater solution $\left(0.01 \mathrm{~g} \mathrm{l}^{-1}\right)$ for $2 \mathrm{~h}$. We concluded that the method provided clients which were almost parasite free on one side while the other side was still highly infected.

After the parasite transfer, fish were placed singly in test aquaria $(91.5 \times 38 \times 38 \mathrm{~cm})$ which contained a polyvinyl-chloride pipe $(16 \mathrm{~cm}$ diameter by $20 \mathrm{~cm}$ ) for shelter. Fish spent 2 to $3 \mathrm{~d}$ in these aquaria before a cleaner fish Labroides dimidiatus was added. Monogeneans moved very little on the client's surface (pers. obs.). One highly infected and 1 normally infected client were checked after $2 \mathrm{~d}$ for parasite migration to the uninfected side using the same methods as described above. No parasites were found on the uninfected side.
Experimental set up. On the day of the experiment, an upright clear plastic (Plexiglas) tube (12 cm diameter by $50 \mathrm{~cm}$ ) was placed into the aquarium at 07:00 h and a Panasonic NV-DS77 digital camera was positioned $80 \mathrm{~cm}$ from the aquarium in such a way that interactions inside the shelter could also be observed. Recording began at 08:00 $\mathrm{h}$, and a cleaner was immediately placed in the Plexiglas tube. During this period, the clients could approach the cleaners and invite inspection ('posing', Losey 1971) but without success. We quantified how much time the clients offered their infected side to the cleaner and how much time they offered their uninfected side. After $15 \mathrm{~min}$, the tube was removed. Cleaning interactions invariably began within the first $2 \mathrm{~min}$ after the removal. The $15 \mathrm{~min}$ following the first body contact between cleaner and client were analysed. The sides of the aquaria acted as mirrors so that the duration of the interactions could be quantified even if the cleaner was behind the client. In addition, we quantified how much time cleaners spent on the infected and the uninfected body sides. The times cleaners spent inspecting the 2 body sides do not add up to the total interaction time (see Fig. 1) as all cleaners spent some time above the clients, providing tactile stimulation by touching the client's dorsal fin with their pelvic and pectoral fins (Potts 1973). For both body sides, we quantified the number of cleaner fish bites, defined as the number of cleaners touching the client surface with their mouth. We quantified bites only for the time periods where we saw the cleaner fish directly on the screen interacting with the client, while we omitted the periods in which the cleaner was visible as a reflection on the aquarium glass only. In the latter situation, it appeared to be too difficult to quantify this behaviour accurately. Note that the increase in variance due to the decrease in information favours the null hypothesis that bite rates are the same on both sides. We used the data on the number of bites and the time the cleaners were directly visible on the screen to calculate a bite rate, i.e. number of bites per $100 \mathrm{~s}$ interaction, for both uninfected and infected body sides.

Nine cleaner fish were tested each with 1 highly and 1 normally infected client, with the 2 fish having parasites on opposite sides. Five cleaners interacted with a normally infected client first, 4 with a highly infected client. Non-parametric statistics were used according to Sokal \& Rohlf (1995). All tests are 2-tailed.

\section{RESULTS}

\section{Cleaning duration}

We found that cleaner fish spent more time interacting with highly infected clients than with normally infected 


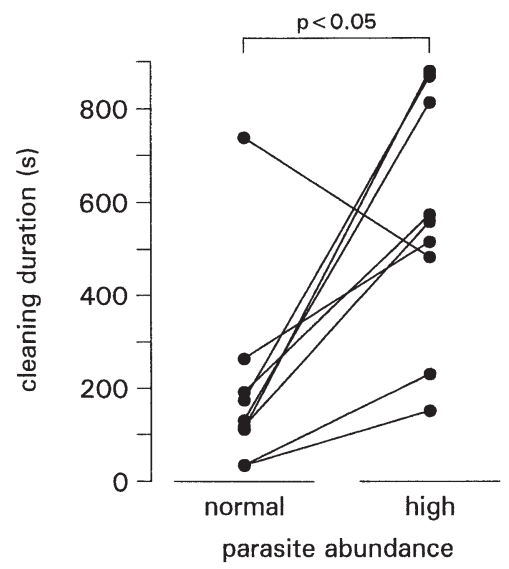

Fig. 1. Total time of interaction during 15 min observations on cleaners interacting with normally infected clients and highly infected clients. Each point represents 1 trial. Lines connect data points from the same cleaner fish

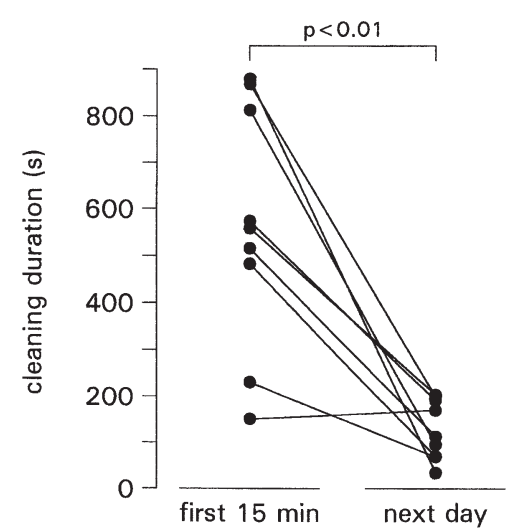

Fig. 2. Total time of interaction during the first $15 \mathrm{~min}$ of cleaners interacting with highly infected clients and during a second 15 min observation period after $25 \mathrm{~h}$. Each point represents 1 trial. Lines connect data from the same cleaner fish-client pairs

clients (Wilcoxon-test, $\mathrm{n}=9, \mathrm{~T}=3, \mathrm{p}<0.02$; Fig. 1). Furthermore, after cleaners and clients were held $25 \mathrm{~h}$ in the aquarium together, cleaning duration was significantly lower between cleaners and originally highly infected clients than at the onset of the experiment (Wilcoxon-test, $\mathrm{n}=9, T=1, \mathrm{p}<0.01$; Fig. 2). After the 25 h, 6 out of 9 originally highly infected clients were parasite free, while the remaining individuals had 1, 2 and 4 parasites, respectively (Bshary \& Grutter 2002).

\section{Inspection time attributed to the infected and the uninfected sides}

Cleaner fish spent more time on the infected sides than on the uninfected sides regardless of parasite load
(Wilcoxon-tests, normally infected clients: $\mathrm{n}=9, T=2$, $\mathrm{p}<0.02$, highly infected clients: $\mathrm{n}=9, T=0, \mathrm{p}<0.01$; Fig. 3). This difference was significantly more pronounced with the highly infected clients than with the normally infected clients (Wilcoxon-test, $\mathrm{n}=9, T=4$, p $<0.05$; Fig. 3).

\section{Feeding bite rates on the infected and the uninfected sides}

Cleaner fish took more feeding bites per unit time on the infected side than on the uninfected side (Wilcoxon-tests, normally infected clients: 1 tie, remaining $\mathrm{n}=8, T=2, \mathrm{p}<0.02$, highly infected clients: $\mathrm{n}=9, T=0, \mathrm{p}<0.01$; Fig. 4).

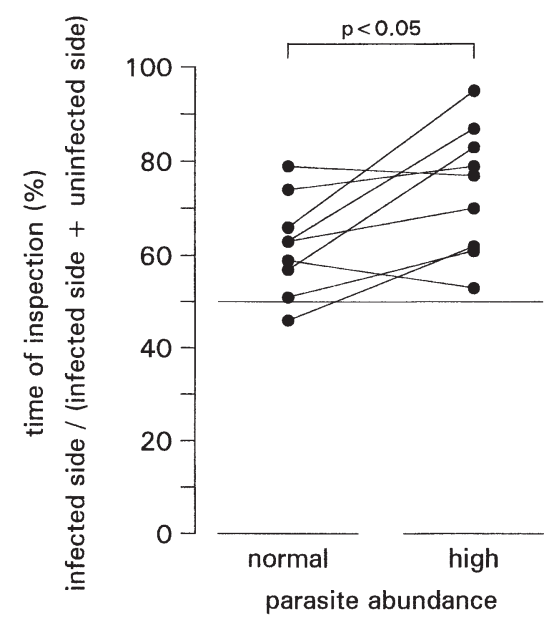

Fig. 3. Percent time cleaners spent inspecting the infected side relative to the uninfected side, when interacting with normally and with highly infected clients. Each point represents 1 trial. Lines as for Fig. 1

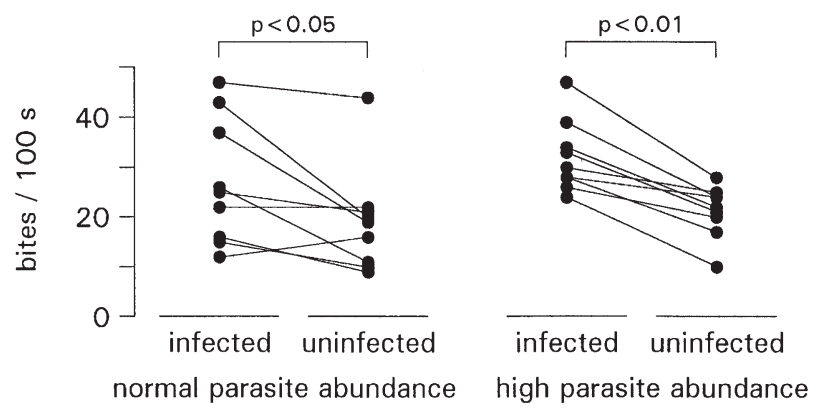

Fig. 4. Cleaner fish bites on the infected and on the uninfected side per $100 \mathrm{~s}$ interaction. Each point represents 1 trial. Lines as for Fig. 1 


\section{Client posing with cleaners in Plexiglas tube}

Clients did not invite inspection by offering their infected sides first significantly more often than their uninfected sides (sign-test, 2 individuals did not pose at all, remaining $\mathrm{n}=16, x=6$, ns). In addition, there was no significant difference in the amount of time clients offered their infected and uninfected body sides to the cleaners, while the latter were still unable to interact (Wilcoxon-test, $\mathrm{n}=16, T=62.5, \mathrm{~ns}$ ). A distinction between highly and normally infected clients did not alter these non-significant results. The median value for clients offering their infected side was $20 \mathrm{~s}$ (range 0 to $284 \mathrm{~s}$ ), while the median value for clients offering their uninfected side was $10 \mathrm{~s}$ (range 0 to $283 \mathrm{~s})$.

\section{DISCUSSION}

Our results show, for the first time, that parasites determine the quality of a food patch for a cleaner when interacting with clients. Inspection behaviour depended on parasite location and mouth contacts (bites) occurred more frequently on the infected side than on the uninfected side. Note that these results are unlikely to be caused by the cleaners avoiding the uninfected side of highly infected clients due to the chemical treatment as normally infected clients were not treated. In addition, we found no evidence that clients actively presented their infected side to cleaners. Apart from the lack of evidence during the phase when cleaners were inside the Plexiglas tube and clients were posing, interactions mainly took place within the shelter, where clients were restricted in their movements. Ctenochaetus striatus is much larger than Labroides dimidiatus, and it appeared that $C$. striatus was unable to match the rapid movements of the cleaners from one body side to the other. As we have shown elsewhere (Bshary \& Grutter 2002), highly infected clients were almost parasite-free after being kept with cleaners for a day. To summarise, cleaners adapt their foraging behaviour to parasite location and do remove the parasites. Assuming that monogeneans are indeed detrimental to their hosts (Thoney \& Hargis 1991), our results thus support the recently growing evidence that clients benefit from cleaning interactions (Grutter 1996, 1999, Sikkel et al. 2000).

Like Gorlick (1984), we found that cleaners spent more time with highly infected clients than with normally infected clients. Whether this difference in inspection duration is due to decisions made by the cleaners or the clients or both is unclear. Nevertheless, this result is in line with the hypothesis that parasite loads are a direct proximate cause influencing clients' decisions to visit cleaners and how long to remain with them (Grutter 2001). The overall number of mouth contacts was much higher than the number of parasites on the clients. While cleaners might need more than 1 bite to remove a parasite, that cannot explain why they fed at all on the uninfected side. It thus appears that they removed material, other than parasites, from clients. Most interestingly, clients rarely appeared disturbed by bites that may have involved the removal of material other than parasites. Only if a cleaner fish bite resulted in a jolt of the client, was the client likely to chase the cleaner in return (Bshary \& Grutter 2002). It could be that many cleaner fish bites represent a mild form of 'cheating' that is tolerated by clients. Still, it could also be that there is some unwanted material (possibly old or dead mucus) on the clients which cleaners can eat without having to fear a negative reaction from clients. Observations (Foster 1985) suggest that clients also seek cleaners to clean wounds and infections. These and our observations indicate that clients might decide to visit cleaners even in the absence of parasites, not to receive tactile stimulation (Losey 1979) but to have unwanted tissue removed (but see Grutter 2001).

In summary our results add further evidence to the hypothesis that client reef fish benefit from interactions with cleaner fish as parasite location influenced cleaner fish foraging behaviour and parasite load influenced cleaning duration. Nevertheless, the proximate mechanisms of clients seeking cleaners remain a puzzling subject for future studies. In addition, there are several lines of evidence that the benefits for clients vary both between study sites (reviews: Losey et al. 1999, Côté 2000) and temporally within each study site (Grutter 1997). It will therefore be challenging to find out whether, apart from differences in parasite abundance (Grutter 1997), other factors also influence the levels of costs and benefits and whether variation in the factors involved lead to parasitic relationships in some areas.

Acknowledgements. We thank the Lizard Island Research Station for their wonderful help and friendship. The work was conducted with permit G97/380. R.B. was supported by the Deutsche Forschungsgemeinschaft (BS 2/2-1 - BS 2/2-4) during fieldwork and by a Marie Curie Fellowship of the EU during writing, A.S.G. by the Australian Research Council. We thank Wolfgang Wickler for making this study possible and 4 anonymous referees for their constructive comments.

\section{LITERATURE CITED}

Arnal C, Côté IM (2000) Diet of broadstripe cleaning gobies on a Barbadian reef. J Fish Biol 57:1075-1082

Arnal C, Morand S, Kulbicki M (1999) Patterns of cleaner wrasse density among three regions of the Pacific. Mar Ecol Prog Ser 177:213-220 
Bshary R (2001) The cleaner fish market. In: Noë R, van Hooff JARAM, Hammerstein P (eds) Economics in nature. Cambridge University Press, Cambridge, p 146-172

Bshary R, Grutter AS (2002) Asymmetric cheating opportunities and partner control in a cleaner fish mutualism. Anim Behav 63:547-555

Côté IM (2000) Evolution and ecology of cleaning symbioses in the sea. Oceanogr Mar Biol Annu Rev 38:311-355

Cushman JH, Beattie AJ (1991) Mutualism: assessing the benefits to hosts and visitors. Trends Ecol Evol 6:193-195

Ernst I, Whittington ID (1996) Hatching rhythms in the capsalid monogeneans Benedenia lutjani from the skin and B. rohdei from the gills of Lutjanus carponotatus at Heron Island, Queensland, Australia. Int J Parasitol 26(11):1191-1204

Feder HM (1966) Cleaning symbiosis in the marine environment. Symbiosis 1:327-380

Foster SA (1985) Wound healing: a possible role of cleaning stations. Copeia 1985:875-880

Gorlick DL (1980) Ingestion of host fish surface mucus by the Hawaiian cleaning wrasse, Labroides phthirophagus (Labridae), and its effect on host species preference. Copeia 1980:863-868

Gorlick DL (1984) Preference for ectoparasite-infected host fishes by the Hawaiian cleaning wrasse, Labroides phthirophagus (Labridae). Copeia 1984:758-762

Gorlick DL, Atkins PD, Losey GS (1987) Effect of cleaning by Labroides dimidiatus (Labridae) on an ectoparasite population at Enewetak Atoll. Copeia 1987:41-45

Grutter AS (1994) Spatial and temporal variations of the ectoparasites of seven reef fish species from Lizard Island and Heron Island, Australia. Mar Ecol Prog Ser 115:21-30

Grutter AS (1995a) Comparison of methods for sampling ectoparasites from coral reef fishes. Mar Freshw Res 46: 891-903

Grutter AS (1995b) Relationship between cleaning rates and ectoparasite loads in coral reef fishes. Mar Ecol Prog Ser 118:51-58

Grutter AS (1996) Parasite removal rates by the cleaner wrasse Labroides dimidiatus. Mar Ecol Prog Ser 130: $61-70$

Grutter AS (1997a) Effect of the cleaner fish Labroides dimidiatus on the abundance and species composition of reef fish. Oecologia 111:137-143

Grutter AS (1997b) Spatio-temporal variation and feeding

Editorial responsibility: Otto Kinne (Editor),

Oldendorf/Luhe, Germany selectivity in the diet of the cleaner fish Labroides dimidiatus. Copeia 1997:346-355

Grutter AS (1999) Cleaner fish really do clean. Nature 398: 672-673

Grutter AS (2001) Parasite infection, not tactile stimulation, proximate cause of cleaning behaviour in reef fish. Proc $\mathrm{R}$ Soc Lond B 268:1367-1374

Limbaugh C (1961) Cleaning symbiosis. Sci Am 205:42-49

Losey GS (1971) Communication between fishes in cleaning symbiosis. In: Cheng TC (ed) Aspects of the biology of symbiosis. University Park Press, Baltimore, p 45-76

Losey GS (1972) The ecological importance of cleaning symbiosis. Copeia 1972:820-833

Losey GS (1977) The validity of animal models: a test for cleaning symbiosis. Biol Behav 2:223-238

Losey GS (1979) Fish cleaning symbiosis: proximate causes of host behaviour. Anim Behav 27:669-685

Losey GS (1987) Cleaning symbiosis. Symbiosis 4:229-258

Losey GS, Grutter AS, Rosenquist G, Mahon JL, Zamzow JP (1999) Cleaning symbiosis: a review. In: Almada VC, Oliveira RF, Goncalves EJ (eds) Behaviour and conservation of litoral fishes. Instituto Superior de Psichologia Aplicada, Lisbon, p 379-395

Potts GW (1973) The ethology of Labroides dimidiatus (Cuv. and Val.) (Labridae, Pisces) on Aldabra. Anim Behav 21: $250-291$

Randall JE (1958) A review of the labrid fish genus Labroides, with descriptions of two new species and notes on ecology. Pac Sci 12:327-347

Sikkel PC, Fuller CA, Hunte W (2000) Habitat/sex differences in time at cleaning stations and ectoparasite loads in a Caribbean reef fish. Mar Ecol Prog Ser 193:191-199

Stephens DW, Krebs JR (1986) Foraging theory. Princeton University Press, Princeton

Sokal RR, Rohlf FJ (1995) Biometry, 3rd edn. Freeman, New York

Thoney DA, Hargis WJ Jr (1991) Monogenea (Platyhelminthes) as hazards for fish in confinement. Annu Rev Fish Dis 1:133-153

Trivers RL (1971) The evolution of reciprocal altruism. Q Rev Biol 46:35-57

Youngbluth MJ (1968) Aspects of the ecology and ethology of the cleaning fish, Labroides phthirophagus Randall. Z Tierpsychol 25:915-932

Submitted: March 28, 2001; Accepted: November 8, 2001 Proofs received from author(s): May 17, 2002 